This copy is for your personal, non-commercial use only.

If you wish to distribute this article to others, you can order high-quality copies for your colleagues, clients, or customers by clicking here.

Permission to republish or repurpose articles or portions of articles can be obtained by following the guidelines here.

The following resources related to this article are available online at www.sciencemag.org (this information is current as of February 27, 2014 ):

Updated information and services, including high-resolution figures, can be found in the online version of this article at:

http://www.sciencemag.org/content/343/6174/999.full.html

Supporting Online Material can be found at:

http://www.sciencemag.org/content/suppl/2014/02/19/science.1247385.DC1.html

This article cites $\mathbf{3 8}$ articles, 8 of which can be accessed free:

http://www.sciencemag.org/content/343/6174/999.full.html\#ref-list-1

This article appears in the following subject collections:

Oceanography

http://www.sciencemag.org/cgi/collection/oceans 
34. J. A. Forrest, ]. Mattsson, Phys. Rev. E Stat. Phys. Plasmas Fluids Relat. Interdiscip. Topics 61, R53-R56 (2000). and Engineering Research Council of Canada, for financial support. We also thank 0. Bäumchen for interesting discussions.
Figs. S1 and S2

Database S1

References $(35,36)$
Acknowledgments: The authors acknowledge the École Normale Supérieure of Paris, the Fondation Langlois, the Chaire Total-ESPCI ParisTech, as well as the Natural Sciences
Supplementary Materials

www.sciencemag.org/content/343/6174/994/suppl/DC1

Materials and Methods
19 August 2013; accepted 3 February 2014 $10.1126 /$ science. 1244845

\section{Rapid Thinning of Pine Island Glacier in the Early Holocene}

\author{
J. S. Johnson, ${ }^{1 *} \dagger$ M. J. Bentley, ${ }^{2,1} \dagger$ J. A. Smith, ${ }^{1}$ R. C. Finkel, ${ }^{3,4}$ D. H. Rood, ${ }^{3,5} \ddagger$ K. Gohl, ${ }^{6}$ \\ G. Balco, ${ }^{7}$ R. D. Larter, ${ }^{1}$ ]. M. Schaefer ${ }^{8,9}$
}

Pine Island Glacier, a major outlet of the West Antarctic Ice Sheet, has been undergoing rapid thinning and retreat for the past two decades. We demonstrate, using glacial-geological and geochronological data, that Pine Island Glacier (PIG) also experienced rapid thinning during the early Holocene, around 8000 years ago. Cosmogenic ${ }^{10}$ Be concentrations in glacially transported rocks show that this thinning was sustained for decades to centuries at an average rate of more than 100 centimeters per year, which is comparable with contemporary thinning rates. The most likely mechanism was a reduction in ice shelf buttressing. Our findings reveal that PIG has experienced rapid thinning at least once in the past and that, once set in motion, rapid ice sheet changes in this region can persist for centuries.

$\mathrm{I}$ ce mass loss from the Pine Island-Thwaites sector dominates the contemporary contribution to sea level from the West Antarctic Ice Sheet (WAIS) $(1,2)$. Pine Island Glacier (PIG) (Fig. 1A) in particular is currently experiencing considerable acceleration, thinning, and retreat (3-6). This has raised concerns over how much ice will be lost to the ocean before the ice stream stabilizes (5-8). Satellite altimetry measurements show an increase in rates of thinning of ice close to the
PIG grounding line from 1.2 to $6 \mathrm{~m}_{\text {year }}{ }^{-1}$ between 2002 and $2007(4,9)$. In addition, thinning has been detected $150 \mathrm{~km}$ upstream of the grounding line (10). The pattern of change is best explained by a dynamic response to increased influx of warm water to the cavity under the ice shelf at of change - and our understanding of dynamic changes - over longer time scales of centuries to millennia is still limited. Consequently, there the glacier front (11-14). However, the record is considerable uncertainty associated with model projections of the future evolution of PIG and hence the rate and timing of future ice loss (15). The geological record provides evidence of styles and rates of past ice sheet change that can provide constraints on the bounds of possible future change (16). In the PIG region, the existing geological record consists largely of marine geological data describing grounding line retreat across the continental shelf (17-21). In contrast, little is known about the terrestrial thinning

${ }^{1}$ British Antarctic Survey, Natural Environment Research Council, High Cross, Madingley Road, Cambridge CB3 OET, UK. ²Department of Geography, Durham University, South Road, Durham DH1 3LE, UK. ${ }^{3}$ Center for Accelerator Mass Spectrometry, Lawrence Livermore National Laboratory, Post Office Box 808 L-397, Livermore, CA 94550, USA. ${ }^{4}$ Earth and Planetary Science Department, University of California, Berkeley, CA 94720, USA ${ }^{5}$ Earth Research Institute, University of California, Santa Barbara, CA 93106, USA. ${ }^{6}$ Alfred Wegener Institute Helmholtz-Centre for Polar and Marine Research, Am Alten Hafen 26, 27568 Bremerhaven, Germany. ${ }^{7}$ Berkeley Geochronology Center, 2455 Ridge Road, Berkeley, CA 94709, USA. ${ }^{8}$ Lamont-Doherty Earth Observatory (LDEO), Columbia University, Route 9W, Palisades, NY 10964, USA. ${ }^{9}$ Department of Earth and Environmental Sciences, Columbia University, New York, NY 10027, USA.

*Corresponding author. E-mail: jsj@bas.ac.uk †These authors contributed equally to this work. ‡Present address: Scottish Universities Environmental Research Centre, Rankine Avenue, Scottish Enterprise Technology Park, East Kilbride G75 0QF, UK.
A

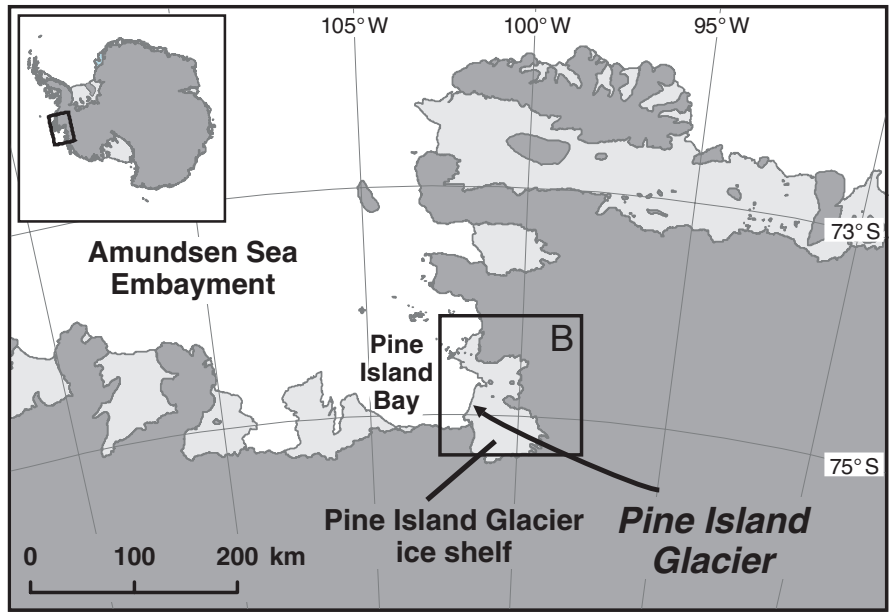

Fig. 1. Location of study area. (A) Map of the Amundsen Sea Embayment, showing location of the study area. The grounded ice sheet is shown in dark gray, and ice shelves are shown in light gray. (Inset) The location within Antarctica. The box shows the area covered by (B). (B) Map of Pine Island Bay, showing flow velocities (31) of Pine Island Glacier and the unnamed outlet glacier flowing through the Hudson Mountains, overlaid on Landsat Image Mosaic of Antarctica imagery (gray scale). Contours are in meters. The grounding line is indicated by the solid black line,

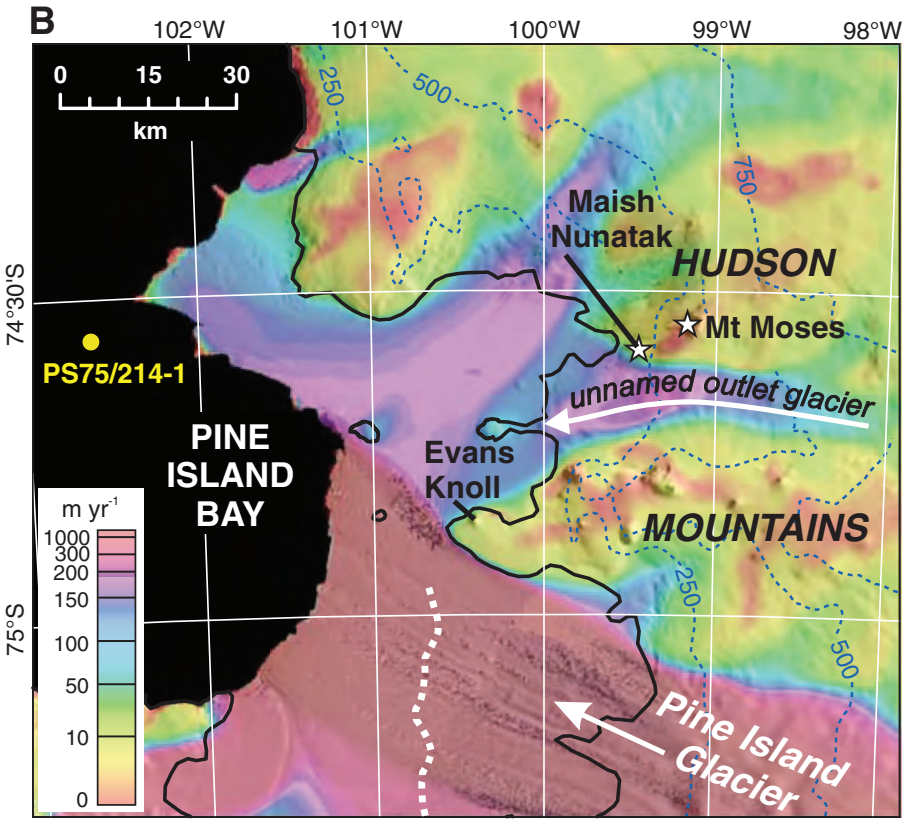

and the crest of the sub-ice shelf ridge (7) is indicated by the dashed white line. The yellow circle indicates marine sediment core site PS75/214-1, which constrains grounding line retreat (before $11.7 \pm 0.7 \mathrm{ka}$ ) from Pine Island Bay (21). 
history of PIG (22) or how the ice stream evolved through the Holocene to the onset of present-day thinning.

Here, we report detailed glacial-geological evidence from the Hudson Mountains (Fig. 1B) for rapid thinning in the PIG system $\sim 8$ thousand years ago (ka). We studied two nunataks, Mount Moses and Maish Nunatak, located close to the northern margin of PIG within $50 \mathrm{~km}$ of its present grounding line (Fig. 1B). An unnamed outlet glacier flows through the Hudson Mountains and feeds into Pine Island Glacier ice shelf (Fig. 1B). In common with many of the ice shelftributary glaciers along the Amundsen Sea coast, the outlet glacier is presently thinning rapidly (at a rate of 80 to $150 \mathrm{~cm} \mathrm{year}^{-1}$ ) (fig. S1) (4). At times when the PIG grounding line was beyond Evans Knoll ( 45 km seaward of its current position) (Fig. 1B), the glacier would have been a tributary to PIG, and thus, changes in its elevation provide a proxy for past elevation changes of PIG. In this way, the Hudson Mountains provide a "dipstick" record of PIG thinning during formerly more advanced positions.

Glacial deposits at both sites consist of scattered erratic cobbles and boulders of granitic lithology resting on basaltic bedrock (fig. S2) (23). Highsensitivity ${ }^{10} \mathrm{Be}$ surface exposure dating (24) was undertaken on 12 erratics collected between 0 and $142 \mathrm{~m}$ above the present ice surface on the two nunataks (fig. S3). Details of chemical procedures, isotopic data, and age calculations are given in (23) and tables S1 to S3. All but one sample - whose anomalously old exposure age ( $\sim 15,800$ years) (table $S 2)$ we attribute to reworking of a previously exposed cobble-yielded early Holocene ${ }^{10} \mathrm{Be}$ ages, in a narrow time interval from $6.0 \pm 0.2$ to $8.1 \pm 0.3 \mathrm{ka}$ (Fig. 2, A, B, and $\mathrm{C}$ ). At Maish Nunatak, exposure ages at all elevations - a range of $100 \mathrm{~m}$ - are indistinguishable. At Mount Moses, the three highest samples yielded exposure ages that are not only indistinguishable over an elevation range of $60 \mathrm{~m}$ but are also indistinguishable from the ages at Maish Nunatak. By "indistinguishable," we mean that we cannot reject the hypothesis that the scatter of each group of ages around the mean results from measurement uncertainty alone (table S3) (23). We interpret the ages as a record of thinning of the outlet glacier flowing through the Hudson Mountains. Given that an ice surface cannot lower infinitely fast, samples at higher elevations must have been exposed for longer than were samples at lower elevations. Our observation of indistinguishable exposure ages over a wide elevation range from two nearby nunataks can therefore only be explained by ice-sheet thinning that was sufficiently rapid to expose the samples instantaneously with respect to the precision of their exposure ages.

In order to determine the thinning rate at our sites, we fitted separate linear age-elevation models to the data from each nunatak (23). Less than $20 \mathrm{~km}$ upstream of the modern grounding line, modeled thinning rates that best fit the exposure age data are 112 and $167 \mathrm{~cm}_{\text {year }}^{-1}$ (Fig. 2D). Our uncertainty analysis shows that these cannot be distinguished from contemporary thinning rates (fig. S1). The early Holocene thinning rates are thus sufficiently high that they imply ice-dynamic change rather than thinning resulting from changes in accumulation and ablation. We infer that previous rapid thinning of the PIG system must have been sustained for several decades, and possibly centuries; our uncertainty analysis indicates $95 \%$ confidence that rapid thinning lasted longer than 25 years (23). If we assume that the early Holocene thinning was monotonic, the results of our fitting procedure suggest that by $7.9 \mathrm{ka}$, the ice sheet surface at Maish Nunatak had lowered to its present-day elevation, and rapid thinning at Mount Moses had ended (fig. S4). The Maish Nunatak data place some constraint on the onset of contemporary thinning. If present rapid thinning rates
Fig. 2. Thinning history of the Pine Island Glacier system. $(\mathbf{A}$ and $\mathbf{B}){ }^{10}$ Be exposure ages of erratics from Mount Moses and Maish Nunatak relative to the local ice surface. Error bars show $1 \sigma$ measurement uncertainties. Dark lines are linear age-elevation relationships that best fit the exposure age data, and the bundles of lighter lines show age-elevation relationships generated by the Monte Carlo uncertainty analysis (23). (C) Relationship between ${ }^{10} \mathrm{Be}$ exposure ages from both nunataks. (Inset) Representative thinning rates on same axes. One sample from Maish Nunatak with an anomalously old age ( 15,800 years) is not shown because its age likely reflects prior cosmic ray exposure (16). (D) Uncertainty distributions for thinning rates for each nunatak, derived from Monte Carlo sim-
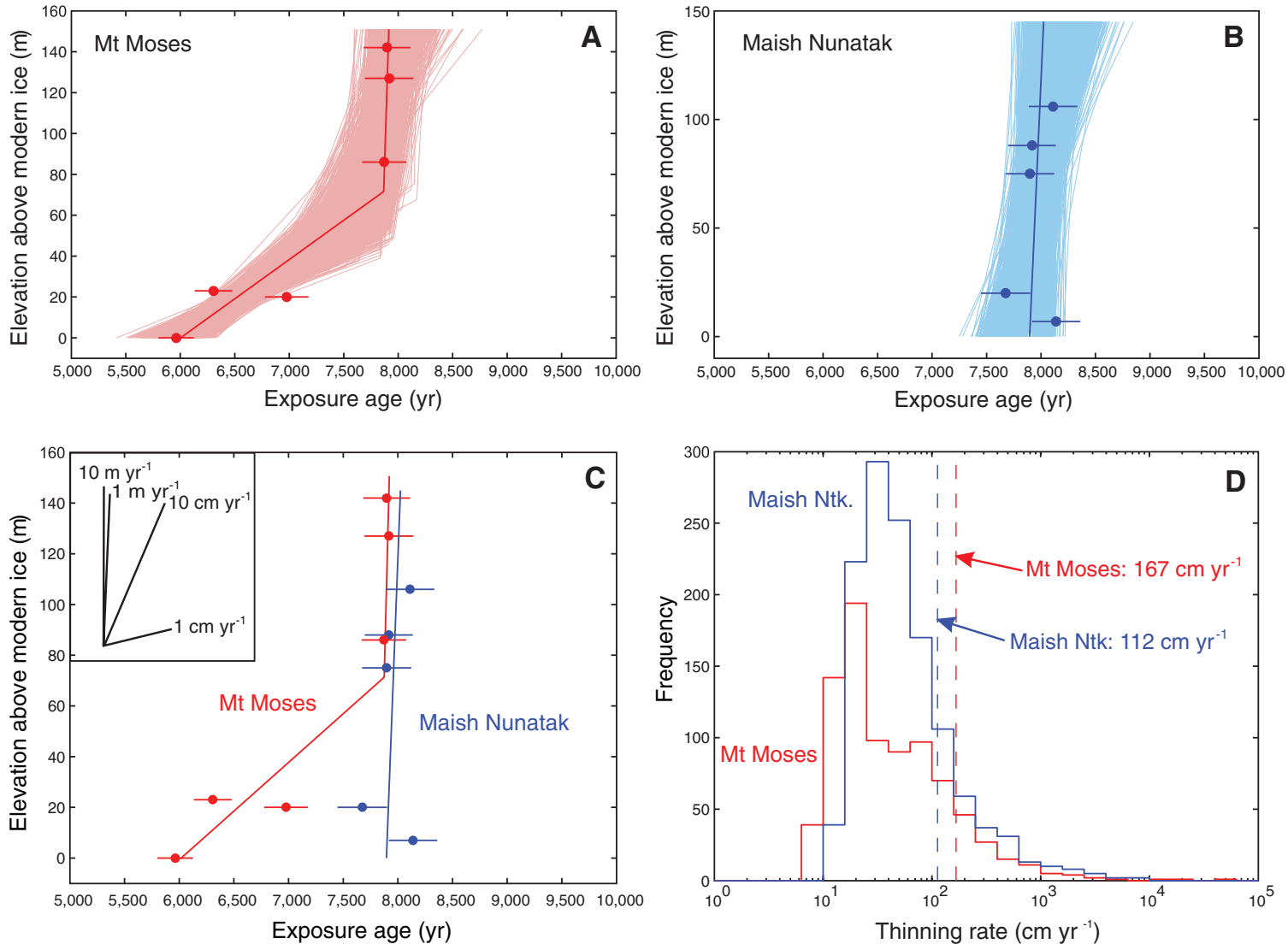

ulations. Dashed lines are best-fit thinning rates. Histogram bins are logarithmically spaced for clarity. $95 \%$ of the Monte Carlo results fell between 8 and $590 \mathrm{~cm}_{\text {year }}{ }^{-1}$ for the period of rapid thinning at Mount Moses, and between 13 and $550 \mathrm{~cm}_{\text {year }}{ }^{-1}$ for thinning at Maish Nunatak. In (A) to
(D), the uncertainty distributions do not include systematic uncertainty on ${ }^{10} \mathrm{Be}$ production rate; errors in estimating production rate would act to shift the entire array of ages equally, without changing the relationship between them. 
have been sustained for several decades, then the ice surface must have been considerably higher when it started. However, if the ice surface was even a few meters above present for a substantial period of the late Holocene, then we would observe erratics with much younger exposure ages at sites adjacent to the modern ice surface than those at higher elevations. Given that this is not the case, if the ice surface was above these samples between $7.9 \mathrm{ka}$ and recent decades, it can only have been so for a time comparable with the precision of the exposure ages ( $\sim 100$ years). Thus, the most likely scenario consistent with our data is that the ice surface was near its present elevation (or possibly lower, because our observations cannot detect periods of thinner ice) between $7.9 \mathrm{ka}$ and the onset of contemporary thinning.

The high thinning rates determined from our exposure ages imply an ice-dynamic change because drivers such as a decrease in accumulation rate or increase in atmospheric temperature would produce a slower response. Marine geological and geophysical studies show that the PIG grounding line had retreated to within, but had not stabilized at, $112 \mathrm{~km}$ of its present position (the core site is shown in Fig. 1B and fig. S5) by $11.7 \pm 0.7 \mathrm{ka}$ (21), and that a ridge beneath PIG ice shelf (Fig. $1 \mathrm{~B}$ and fig. S5) acted as a pinning point for the grounding line before the 1970s (7). Therefore, potential hypotheses for the mechanism of an early Holocene ice-dynamic change could be (i) rapid migration of the PIG grounding line resulting from decoupling from a topographic high or (ii) reduction in ice shelf buttressing.

First, we discuss the effect of subglacial topography. This can influence the style of ice stream retreat - for example, by providing topographic highs on which pinning can occur (25) and by constraining ice stream width $(26,27)$. Although the marine geological data constrain retreat of the grounding line landward from the core site to the sub-ice shelf ridge only to sometime between $11.7 \mathrm{ka}$ and the 1970s, they do not preclude that the retreat was associated with inland thinning at $\sim 8 \mathrm{ka}$. However, there are no topographic highs seaward of the sub-ice shelf ridge where the grounding line might have been pinned after $11.7 \mathrm{ka}$ (fig. S5) and from which detachment could have triggered the dynamic thinning inland. Therefore, although grounding line retreat may have been associated with the early Holocene thinning, decoupling of the PIG grounding line from a topographic high [hypothesis (i)] is unlikely to have been the trigger for it.

Alternatively, thinning may have been the consequence of reduction in buttressing by an ice shelf. Marine sediments have been used to infer the presence of an ice shelf across the middle shelf of the Amundsen Sea before $\sim 10.6 \pm 0.3 \mathrm{ka}$ (fig. S5A) (19). Although the available chronological data cannot resolve when that ice shelf finally retreated into inner Pine Island Bay, one study suggests that it persisted there until $\sim 7 \mathrm{ka}$ (19). Glaciers in the Amundsen Sea Embayment and elsewhere in Antarctica have responded to recent ice shelf thinning with acceleration of flow, grounding line retreat, and thinning (14). Similarly, subsequent retreat or weakening (such as by thinning) of a buttressing ice shelf in Pine Island Bay could have triggered the dynamic thinning in the Hudson Mountains at $\sim 8 \mathrm{ka}$. Reduction in ice shelf buttressing would most likely have been initiated by enhanced basal melting in response to inflow of warm Circumpolar Deep Water, as is suggested to account for present thinning (11). We favor hypothesis (ii) as the most likely mechanism for early Holocene ice-dynamic change, but we cannot rule out more complicated mechanisms. For example, it is possible that thinning of the outlet glacier may be related to its separation from PIG.

These results have implications for understanding how the Pine Island-Thwaites sector of the WAIS is likely to evolve in coming decades to centuries. The knowledge that PIG has previously undergone sustained dynamic thinning, followed by relative stabilization over several millennia before the onset of contemporary thinning, suggests that the PIG system can respond quickly to environmental change by abrupt, discontinuous, and stepwise retreat. Continued thinning may lead to an even more dramatic response if a dynamic threshold, such as a critical ice shelf thickness or ice flow rate, is exceeded. In addition, the rate and magnitude of early Holocene thinning is consistent with model-based estimates of future PIG thinning sustained over the coming century $(28,29)$, a time scale over which the magnitude of sea-level rise most concerns policymakers. In a wider context, the pattern of abrupt past thinning of PIG contrasts with evidence for slower and steadier Holocene deglaciation of other regions of the WAIS $(16,30)$, hinting that a considerable part of any WAIS contribution to sea-level rise in the early Holocene may have come from its Amundsen Sea sector.

The data presented here demonstrate that thinning of PIG at a rate comparable with that over the past two decades is rare but not unprecedented in the Holocene. Moreover, in contrast to previous glacial-geological work in Antarctica that has provided average thinning rates only over millennial time scales, our data are precise enough to show that rapid thinning of PIG was sustained for at least 25 years, and most likely for much longer. These data provide a long-term context for contemporary thinning of PIG, suggesting that ongoing ocean-driven melting of PIG ice shelf can result in continued rapid thinning and grounding line retreat for several more decades or even centuries.

\section{References and Notes}

1. M. A. King et al., Nature 491, 586-589 (2012)

2. A. Shepherd et al., Science 338, 1183-1189 (2012).

3. E. Rignot, Geophys. Res. Lett. 35, L12505 (2008).

4. H. D. Pritchard, R. J. Arthern, D. G. Vaughan,

L. A. Edwards, Nature 461, 971-975 (2009).

5. D. Wingham, D. W. Wallis, A. Shepherd, Geophys. Res. Lett. 36, L17501 (2009).
6. J. W. Park et al., Geophys. Res. Lett. 40, 2137-2142 (2013).

7. A. Jenkins et al., Nat. Geosci. 3, 468-472 (2010)

8. I. Joughin, R. B. Alley, Nat. Geosci. 4, 506-513 (2011)

9. R. Thomas et al., Science 306, 255-258 (2004).

10. A. Shepherd, D. J. Wingham, ]. A. D. Mansley, H. F. Corr, Science 291, 862-864 (2001).

11. S. S. Jacobs, A. Jenkins, C. F. Giulivi, P. Dutrieux, Nat. Geosci. 4, 519-523 (2011).

12. A. J. Payne, A. Vieli, A. Shepherd, D. J. Wingham, E. Rignot, Geophys. Res. Lett. 31, L23401 (2004).

13. A. Shepherd, D. Wingham, E. Rignot, Geophys. Res. Lett. 31, L23402 (2004).

14. H. D. Pritchard et al., Nature 484, 502-505 (2012).

15. Intergovernmental Panel on Climate Change, in Climate Change 2007: The Physical Science Basis. Contribution of Working Group I to the Fourth Assessment Report of the Intergovernmental Panel on Climate Change, S. Solomon, et al., Eds. (Cambridge Univ. Press, Cambridge, 2007)

16. ]. O. Stone et al., Science 299, 99-102 (2003).

17. A. L. Lowe, ]. B. Anderson, Quat. Sci. Rev. 21, 1879-1897 (2002).

18. A. G. C. Graham et al., J. Geophys. Res. 115, F03025 (2010).

19. A. E. Kirshner et al., Quat. Sci. Rev. 38, 11-26 (2012).

20. M. Jakobsson et al., Quat. Sci. Rev. 38, 1-10 (2012).

21. C.-D. Hillenbrand et al., Geology 41, 35-38 (2013).

22. J. S. Johnson, M. J. Bentley, K. Gohl, Geology 36, 223-226 (2008).

23. Materials and methods are available as supplementary materials on Science Online.

24. ]. M. Schaefer et al., Science 324, 622-625 (2009)

25. K. J. Tinto, R. E. Bell, Geophys. Res. Lett. 38, L20503 (2011).

26. S. S. R. Jamieson et al., Nat. Geosci. 5, 799-802 (2012).

27. G. H. Gudmundsson, ]. Krug, G. Durand, L. Favier O. Gagliardini, Cryosphere 6, 1497-1505 (2012).

28. I. Joughin, B. E. Smith, D. M. Holland, Geophys. Res. Lett. 37, L20502 (2010)

29. R. M. Gladstone et al., Earth Planet. Sci. Lett. 333-334, 191-199 (2012).

30. M. J. Bentley et al., Geology 38, 411-414 (2010).

31. E. Rignot, ]. Mouginot, B. Scheuchl, MEaSUREs InSAR-Based Antarctica Ice Velocity Map (National Snow and Ice Data Center, Boulder, CO, 2011).

Acknowledgments: The data presented here are archived in the supplementary materials. The project was conceived and developed by M.J.B. and R.D.L. Fieldwork and sampling were planned and undertaken by M.J.B., J.A.S., and J.S.]. K.G. led the cruise (RV Polarstern Expedition ANT-XXVI/3). J.S.] processed the samples and interpreted the data, with direction from J.M.S., and analyses were performed by R.C.F. and D.H.R. G.B. developed the Monte Carlo simulations for Fig. 2 and fig. S4. M.J.B. and J.S.]. wrote the first draft, and all authors contributed to the interpretation and writing of the paper. This work forms part of the British Antarctic Survey program "Polar Science for Planet Earth," funded by the Natural Environment Research Council, and was made possible by a Marie Tharp Fellowship in Earth, Environmental, and Ocean Sciences at Columbia University Earth Institute/ Lamont-Doherty Earth Observatory, awarded to ].S.]. The fieldwork was supported by the research program PACES, Topic 3 "Lessons from the Past" of the Alfred Wegener Institute. This is LDEO publication 7577

\section{Supplementary Materials}

www.sciencemag.org/content/343/6174/999/suppl/DC1

Materials and Methods

Figs. S1 to $\mathrm{S} 5$

Tables S1 to S3

References (32-41)

18 October 2013; accepted 5 February 2014

Published online 20 February 2014;

10.1126/science. 1247385 